\title{
A PRÁTICA DE MULTILETRAMENTOS NO CONTEXTO ESCOLAR PÚBLICO: RELATANDO EXPERIÊNCIAS NA PRODUÇÃO DE NARRATIVAS DIGITAIS EM AULAS DE LÍNGUA PORTUGUESA
}

\author{
Anidene de Siqueira Cecchin (PPGTER/UFSM, anicecchin@gmail.com) \\ Prof. Dra. Susana Cristina dos Reis (DLEM/UFSM, suzireis@cead.ufsm.br)
}

Resumo: O trabalho de produção escrita utilizando narrativas digitais é uma abordagem de ensino pouco utilizada no contexto escolar. Tendo por base esse pressuposto, este trabalho tem por objetivo reportar práticas didático-pedagógicas de multiletramentos, por meio da produção de narrativas digitais, as quais se orientam a partir do processo de construção e desconstrução de gêneros, com vistas a desenvolver uma abordagem pedagógica de ensino sistematizada em etapas. Essas experiências foram realizadas nos últimos três anos no contexto escolar de uma escola pública, nas quais foram construídas narrativas digitais que abordassem os diferentes gêneros, tais como: Relato Pessoal; Relato de Viagem; Documentário Narrativo. Os resultados dessas experiências apontam para motivação dos alunos na escrita criativa ao usar tecnologias, bem como no aperfeiçoamento de competências e habilidades exigidas para interagir na contemporaneidade por meio da linguagem e multiletramentos na sala de aula.

Palavras-chave: Narrativa Digital. Produção Textual. Multiletramentos.

\section{THE PRATICE OF MULTILITERACIES IN A PUBLIC SCHOOL: REPORTING EXPERIENCES OF DIGITAL STORYTELLING PRODUCTION IN PORTUGUESE CLASSES}

\begin{abstract}
The process of textual production using digital narratives is a not well-known approach explored in the school context. Based on this, this article aims to report pedagogical practices of multiteracies by producing digital narratives that are oriented by the process of constructing and deconstructing genres as an alternative to develop a new pedagogical approach to teaching it systemically. The experiences were realized in the last three years in a public school by constructing digital genres such as personal narratives, travel reports, and documentaries. The results of these experiences show student's motivation to develop creative writing by using technologies as well as to improve student's competences and skills necessary to interact in the contemporary society by using language and multiliteracies in the classroom.
\end{abstract}

Keywords: Digital Storytelling. Textual Production. Multiliteracies

\section{Introdução}

No atual contexto escolar, aliar produção textual à tecnologia para construção de conhecimentos em Língua Portuguesa é uma atividade desafiante, tanto para os alunos que as executam, quanto para os professores que as planejam. Para isso, requer-se pressupostos teóricos que fundamentem o trabalho docente, mais especificamente, para desenvolver atividades de modo que estas capacitem o aluno a explorar as diversas linguagens e seus usos na contemporaneidade, promovendo letramentos múltiplos.

V. $12 \mathrm{~N}^{\mathrm{o}} 2$, dezembro, 2014 
Ao mencionar as diferentes linguagens, estamos nos referindo à realização de um trabalho diferenciado que pressupõe explorar recursos multimodais e os multiletramentos (Rojo, 2012; Cope e Kalantzis, 2009; Motta-Roth e Hendges, 2010), assim como novos caminhos para o ensino da produção textual ao utilizar recursos proporcionados pela tecnologia em sala de aula, permitindo aos educandos relatar suas histórias (Cecchin e Reis, 2013). Porém, é necessário inovar as práticas pedagógicas para ensinar a linguagem e primar pelo uso da Língua para produção de sentido.

Para Kenski (2012) “tecnologias são indispensáveis na educação” e é a integração da tecnologia no contexto escolar que possibilita construir uma nova escola, capaz de formar cidadãos conscientes de seu papel na sociedade, com competências e habilidades que os qualifiquem a interagir no mundo moderno. Tendo por base esses pressupostos, percebemos a necessidade de investigar abordagens pedagógicas que resultem em práticas inovadoras com o objetivo de inserir, efetivamente, no contexto escolar a tecnologia. Diante isso, percebemos que a produção textual por meio de narrativas digitais (Paiva, 2010; Ohler, 2008) pode ser uma alternativa, haja vista que aprendemos e ensinamos por meio das histórias que ouvimos, criamos e/ou vivenciamos para retratar nossas subjetividades, ao reportar a outras pessoas nossas ações no mundo.

Portanto, o presente trabalho reporta resultados das experiências de práticas de multiletramentos realizadas no contexto escolar, em momentos distintos, entre os anos de 2012 a 2014, com alunos de uma escola da Rede Pública da cidade de Santa Maria/RS, por meio da produção de narrativas digitais para o ensino de produção textual e Língua Portuguesa (LP). Ao realizar essa pesquisa, integramos ao uso de narrativas digitais, princípios da pedagogia de gêneros (Motta-Roth, 2006; Hyland, 2007; Cope e Kalantzis, 2009) como forma de orientar as atividades. Para alcançarmos esse objetivo, buscou-se desenvolver uma abordagem pedagógica de produção textual em etapas, que explorasse o uso de recursos tecnológicos para a produção textos que expressassem as vivências do aluno por meio de narrativas.

Assim, neste artigo, primeiramente, abordamos pressupostos teóricos que fundamentam as práticas didático-pedagógicas aplicadas. Para tal, discutimos o processo de produção textual embasado em gêneros, os multiletramentos no contexto escolar e as narrativas contemporâneas. Na sequência, apresentamos os resultados obtidos, propondo reflexão e análise sobre eles até o presente momento.

\section{0 processo de produção textual embasado em gêneros}

As práticas pedagógicas de produção textual na escola constituem-se como uma tarefa desafiadora aos educadores que buscam por fundamentação para suas ações de ensino e, ao mesmo tempo, envolvam os alunos em seu processo de desenvolvimento. Diante disso, é preciso integrar motivação, escrita, ensino e aprendizagem da Língua, para que se faça o uso das múltiplas linguagens, presentes na contemporaneidade.

Motta-Roth (2006, p. 4) sugere que "o ato de escrever é uma atividade social” e, ao realizar o trabalho embasado em gêneros, esse processo precisa dar forma e finalidade ao ato de escrever. Não há como aproximar o aluno da escrita sem que ele identifique a finalidade dessa tarefa, que é a de comunicar seus propósitos ao mundo com criticidade e criatividade. Para que isso ocorra, é necessário fundamentar o processo de escrita em gêneros, preparando os estudantes para fazer o uso das diversas linguagens como forma de resolver problemas práticos de seu dia a dia, por exemplo, ao escrever um e-mail, uma carta 
de solicitação e/ou reclamação ou ao organizar inclusive seu Curriculum Vitae. Nessa perspectiva, o aluno escreve vislumbrando sua necessidade de comunicar-se e apodera-se da linguagem para, em prol das necessidades básicas que a sociedade lhe exige, utilizá-la nas diferentes situações e eventos comunicativos que a vida lhe proporciona.

Motta-Roth (2006) defende, ainda, a proposta de desenvolver um trabalho de produção textual voltado para as práticas sociais como forma de expor nossa "visão de mundo". Com isso, a escrita passa a ter um propósito definido, pois embasamos o seu processo de produção nas tarefas do dia a dia, voltadas para suprir necessidades básicas, usando a linguagem para comunicar para a vida (Hyland, 2007). Dessa forma, oferecemos condições de desenvolvimento de habilidades linguísticas e comunicativas que capacitem os alunos a interagir no mundo.

Diante disso, é notório e urgente que o processo de escrita seja reconfigurado e alicerçado em práticas de ensino que engajem os alunos, como forma de prepará-los para exercer sua cidadania, concebendo-os como sujeitos crítico-participativos. Para tanto, é preciso implementar abordagens que os desafiem a desenvolver suas habilidades para expressar-se ao reportar, por meio da produção de narrativas digitais, suas experiências vividas e projetando expectativas.

\section{Multiletramentos no contexto escolar}

Tendo por base o uso da linguagem e suas diversidades, na atual sociedade é responsabilidade da escola aproximar o aluno e a tecnologia para construir conhecimentos sobre as diferentes linguagens que emergem na sociedade hipermidiática. Para isso, tornase essencial ofertar um ensino que considere o uso da LP nas práticas do dia a dia. Cope e Kalantzis (2009, p. 168) referem-se a educação de qualidade como "uma das principais fontes de equidade social" e defendem seu uso para diminuir as diferenças e desigualdades existentes na sociedade, pois, por meio dela, pode-se promover a inclusão dos alunos na sociedade.

Ao destacarmos um ensino inovador da linguagem na produção de textos, não podemos ignorar que o crescente uso das tecnologias nos permite uma nova dimensão na arte de contar nossas histórias: a digital. Diante disso, exigem-se novos letramentos (Cope e Kalantzis, 2009; Rojo, 2012), os quais são necessários para construção de relatos que reportem nossas vivências, integrando o uso das diversas semioses que constituem os textos na atualidade, dentre elas, a escrita, o som, a imagem, os efeitos e/ou animações, que possibilitam criar textos hipermidiáticos.

Cope e Kalantzis (2009, p. 165) destacam que "com as novas práticas de comunicação, novos letramentos têm surgido”, os quais exigem novas concepções dos processos de ensinar e aprender e, consequentemente, novas posturas de trabalho na escola. $\mathrm{Na}$ mesma direção, Rojo (2012, p. 13) enfatiza a necessidade de promover multiletramentos, especialmente por existirem dois tipos importantes de multiplicidades presentes em nossas sociedades: “a multiplicidade cultural das populações e a multiplicidade semiótica de constituição dos textos” (Rojo, 2012, p. 13).

Para Motta-Roth e Hendges (2010, p.61) multiletramentos são competências necessárias na contemporaneidade, haja vista que precisamos entender e analisar os diversos discursos que se apresentam na atualidade, como forma de interagir na sociedade. Diante disso, cabe à escola promover o aperfeiçoamento de tais competências, contribuindo significativamente para inserir o aluno no contexto social. Nessa mesma perspectiva, 
Heberle (2012) destaca que a linguagem verbal não ocorre isoladamente, pois as diferentes formas de expressar nossos pensamentos exigem novas posturas diante das práticas de leitura e escrita, as quais também exigem habilidades de multiletramentos.

\section{A arte de criar narrativas digitais multimodais}

Contar histórias é uma arte e encanta o homem desde a antiguidade. As histórias fazem parte da nossa vida e nos permitem interagir com o mundo por meio da linguagem e suas diversas modalidades, presentes na atualidade. Assim, ao ouvir, criar e recriar nossos relatos, ensinamos e aprendemos. No contexto escolar, ao explorar narrativas multimodais instigamos a busca pelo conhecimento, permitindo aprimorarmos a capacidade de externar nossas vivências com criatividade, ao mesmo tempo em que promovemos o uso da linguagem para historiar.

Com o crescente uso da tecnologia e da internet, "novas formas de produção de texto emergem nas práticas sociais da linguagem” (Paiva, 2010, p.184), o que implica uma nova postura em relação aos processos de ensino e aprendizagem da Língua. Associado a isso, a antiga arte de contar histórias ganha uma nova dimensão, a digital e abarca o uso da multimodalidade para narrar. Para Paiva (2010), ao narrar usamos diferentes metáforas e sentidos, por exemplo, o tom da voz, os gestos, a palavra escrita, as fotos, os vídeos e, inclusive, as lembranças de lugares ou situações vividas.

Textos multimodais apresentam-se de forma textual não linear (Paiva, 2010), os quais enriquecem a produção e ampliam formas de expressão, possibilitando a construção de uma rede de sentidos, de modo hipertextual e multimodal. Nesse sentido, concordamos com a autora quando a mesma caracteriza as narrativas multimodais como uma "nova forma de produção de texto” (Paiva, 2010, p.184), denominando-as, também, como "um gênero emergente” (Paiva, 2010, p. 185), principalmente por entendermos que esse novo gênero, surge a partir de novas práticas do contexto digital e constitui-se pela interrelação e hiperconexão entre várias linguagens.

Na mesma perspectiva, Ohler (2008, p. 13) afirma que “narrativa digital ajuda

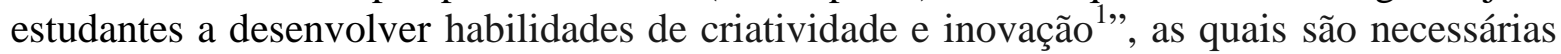
para a vida moderna, portanto, elaborar narrativas com o uso de recursos tecnológicos possibilita motivar e engajar os alunos no processo da escrita em atividades que vem ao encontro das necessidades da sociedade, que vive na era digital.

Na tentativa de integrar o trabalho de elaboração de narrativas multimodais e o ensino da Língua baseada na pedagogia de gêneros, buscando promover de forma lúdica o uso da Língua e multiletramentos, de modo que o aluno escreva significativamente para alguém ou para satisfazer uma necessidade, propomos no contexto de sala de aula de uma escola pública o desenvolvimento de práticas pedagógicas que considerem a produção de narrativas digitais no ensino de LP. Para isso, na sequência relatamos e discutimos como temos realizado essa experiência ao oportunizar aos alunos a produção de narrativas digitais multimodais e o ensino de produção textual em LP.

\section{Reportando as práticas de multiletramentos realizadas}

\footnotetext{
1 "Digital storytelling helps students develop creativity and innovation skills"
} 
Este estudo tem caráter qualitativo e, segundo Oliveira (2007) implica em um processo de reflexão e análise da realidade para a compreensão do processo em seu contexto. Nessa perspectiva configura-se como: a) um estudo de caso, pois investiga não só uma unidade delimitada e contextualizada, mas também o que ela representa no todo; b) uma pesquisa-ação participativa, pois tem como foco investigar alternativas que orientem decisões e ações do professor, no seu contexto de atuação a partir da aplicação desenvolvida.

As práticas didático-pedagógicas reportadas foram realizadas em uma escola da Rede Estadual de Ensino, na cidade de Santa Maria/RS. Os participantes dessa pesquisa compreendem alunos do Ensino Médio (EM), os quais são adolescentes entre 15 e 17anos e a professora da turma. As práticas pedagógicas aconteceram na sala de aula e na sala de informática da referida escola em momentos distintos, as quais compreendem: a) a primeira experiência, realizada no ano de 2012, com alunos do $1^{\mathrm{a}}$ ano do EM, na qual os alunos trabalharam com o gênero Relato Pessoal; b) a segunda experiência, desenvolvida no ano de 2013, com a mesma turma de alunos, no $2^{\circ}$ ano do EM. Nessa etapa foram produzidos Relatos de Viagem, como forma de aproveitar o passeio de estudos que os alunos fizeram à cidade de Rio Grande; c) a terceira experiência, ainda em desenvolvimento, acontece na mesma instituição de ensino, entretanto, com outra turma do $2^{\circ}$ ano do EM. Neste momento, os alunos produzem documentários narrativos que enfocam o tema "O mundo que eu tenho e/ou o mundo que eu quero”.

Para realizar o presente estudo, foram utilizados dois instrumentos de coleta de dados online: um questionário diagnóstico, para explorar o contexto de aplicação da prática pedagógica, assim como a fluência digital dos participantes; e um questionário de avaliação, para avaliar o desenvolvimento do processo aplicado. Os referidos documentos exploratórios serviram, também, como instrumento de análise, além das produções dos alunos.

Ao propor a produção de narrativas digitais para o ensino de LP, foram utilizados os seguintes softwares/recursos: a) o Google Drive para o preenchimento de questionários, bem como a escrita e compartilhamento dos textos iniciais e seus roteiros; b) o Movie Maker, software para a produção dos vídeos com os textos, imagens e som; c) o buscador Google para seleção de imagens e músicas retiradas da internet; d) fotos de autoria dos próprios alunos.

Na tentativa de sistematizar o trabalho realizado de produção de textos multimodais, adotamos como critério de elaboração e avaliação da proposta pedagógica de ensino por meio de narrativas digitais, as etapas de produção de material didático digital (MDD), elaborada pelo Grupo de pesquisa CNPq - NUPEAD - Núcleo de Pesquisa, Ensino e Aprendizagem de Línguas a Distância, da Universidade Federal de Santa Maria. As etapas de elaboração de MDD compreendem: Análise, Planejamento do protótipo, Design da interface, Testagem/pilotagem do protótipo, Re(design), Aplicação e Avaliação (Reis e Gomes, 2014).

Na primeira etapa de elaboração de MDD, que compreende a Análise, aplicamos o questionário de diagnóstico com o objetivo conhecer o público alvo e explorar fluência digital dos participantes, assim como traçar o perfil do aluno e seus conhecimentos em relação às ferramentas tecnológicas. Após, na etapa seguinte, tendo por base as respostas obtidas no questionário diagnóstico foram planejadas as atividades para que pudéssemos dar andamento ao trabalho. 
Na experiência de 2012, os alunos nunca haviam participado da produção de textos hipermidiáticos, mas manifestaram interesse em criar suas narrativas. Assim, a professora da turma criou um blog “Tic Criar"” para postar as tarefas a serem realizadas pelos alunos e para estabelecer a interação no ambiente da sala de aula, conforme já reportado no primeiro artigo de Cecchin e Reis (2013). Essa ferramenta, também, foi utilizada na segunda experiência.

Na etapa de planejamento focalizou-se o gênero em estudo. Para isso, nas três experiências foram trabalhados: na primeira, o Relato Pessoal; na segunda, o Relato de Viagem; e, na terceira, o Documentário Narrativo, no qual se destacou a desconstrução e construção desses gêneros, enfocando suas características específicas, funcionalidades, veículo de publicação e público alvo, para o qual foram planejadas as atividades. Para iniciar, a professora da turma partiu da análise de textos impressos e digitais, estabelecendo suas semelhanças e diferenças, assim como os usos dos elementos linguísticos que os compõem. Seguindo o sistema de trabalho em etapas, os alunos testam as atividades propostas no blog e, na etapa da avaliação foi possível repensar a prática desenvolvida e apontar aspectos positivos e/ou negativos, para fundamentar e organizar a terceira experiência para que pudéssemos repensar e aprimorar a metodologia.

A partir dos dados coletados e dos materiais produzidos pelos alunos nas duas primeiras práticas, foi possível organizar e planejar a terceira experiência, com o intuito de investigar uma abordagem para o ensino de produção textual por meio de narrativa digital e propor um projeto para sua aplicação, também embasado em etapas de desenvolvimento. Para isso, sistematizamos a abordagem em três momentos distintos, denominando-os de “Fase de produção de Narrativas Digitais” (ver figura 5).

Para iniciar a aplicação da terceira prática didático-pedagógica, na Fase I iniciamos com a leitura e análise do gênero em foco, sua desconstrução e construção, bem como seus usos, funcionalidades e público envolvido. Nessa fase, os alunos produziram textos sobre a temática "O mundo que eu tenho e/ou quero", organizando o pensamento em relação à tarefa solicitada, que era a produção de textos narrativos hipermidiáticos para compor a construção conjunta de um documentário. A seguir, na Fase II, iniciou-se a produção das narrativas que comporiam o documentário da turma.

Vale ressaltar que a terceira experiência está em desenvolvimento e está em processo final de aplicação, pois os alunos estão organizando a segunda versão de seus vídeos, após as correções realizadas. Essas experiências possibilitam elaborar uma proposta sistemática de abordagem pedagógica para o ensino de produção textual por meio de narrativa digital.

\subsection{Reflexões sobre as experiências realizadas}

Sabemos que a aprendizagem ocorre a partir das relações estabelecidas e da interação entre os participantes dos processos de ensino e aprendizagem, que tem o aluno como centro e o professor como orientador do processo de aprendizagem. Dessa forma, ao abordar o uso de narrativa digital como recurso para qualificar o processo de ensino, podese afirmar que a experiência de produção de narrativas, não só motivará o aluno a realizar as tarefas relacionadas à escrita, como tornará esse processo prazeroso tanto para o aluno quanto para o professor.

${ }^{2}$ www.ticcriar.blogspot.com.br 
Ao trabalhar com textos hipermidiáticos para relatar vivências, desenvolve-se a criatividade/criticidade e permite aos alunos criar textos híbridos constituídos de múltiplas linguagens, bem como os capacita a interagirem por meio das diferentes semioses à disposição na sociedade, ao mesmo tempo em que os desafia a refletirem sobre seus atos/ações e práticas realizadas enquanto cidadãos conscientes e atuantes na sociedade. Destacamos que o uso da produção de narrativas multimodais proporciona integração, ao utilizar a linguagem para criar/editar/compartilhar os trabalhos produzidos. Dessa forma, o aluno aprende a se manifestar na Língua, fazendo o uso de diferentes linguagens proporcionadas pela tecnologia.

Tendo por base os pressupostos abordados, podemos inferir que os recursos midiáticos configuram-se como fortes aliados nos processos de ensino e aprendizagem, proporcionando aulas agradáveis, descontraídas, nas quais o professor e aluno aprendem e ensinam mutuamente. Podemos afirmar, ainda, que alunos motivados aprendem melhor e conseguem criar e recriar, utilizando o conhecimento adquirido para interagir com os demais, formando uma rede de aprendizagem. Percebemos isso, a partir de alguns depoimentos dos alunos, descritos na etapa de avaliação da primeira experiência, representado abaixo.

$$
\begin{aligned}
& \text { “... achei muito interessante essa proposta de ensino.” (aluno 1) } \\
& \text { “... foi bom, foi um meio mais interessante de aprender.” (aluno 2) }
\end{aligned}
$$

Ao analisar os textos produzidos na primeira experiência, os quais contemplam o gênero Relato Pessoal, observamos narrações e temas diversificados. É possível encontrar histórias familiares, amorosas ou problemáticas, que denotam seus anseios, dúvidas e carências, revelando o cunho emocional das narrativas digitais. As Figuras 1 e 2 abaixo representam algumas dessas narrativas que produzem as temáticas.

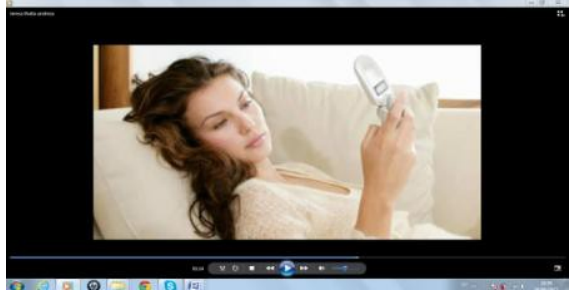

Figura 1: Narrativa de um aluno

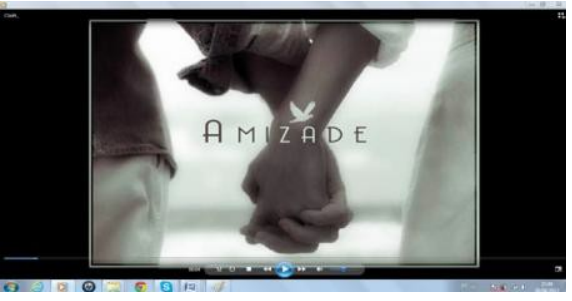

Figura 2: Narrativa de um aluno sobre a amizade

A partir dos temas escolhidos pelos alunos, podemos perceber a subjetividade e o apelo emocional de cada um, reforçados pelas imagens, a trilha sonora, que fazem um convite ao leitor. Os resultados obtidos na segunda experiência reforçam a primeira, pois os alunos ao reportar no Relato de Viagem o passeio feito por intermédio da escola à cidade de Rio Grande/RS explicitaram quão significativa essa experiência tornou-se para eles, conforme mostram as Figuras 3 e 4. 


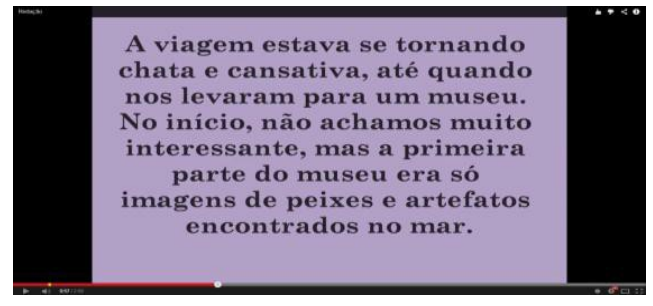

Figura 3: Relato de viagem de um aluno

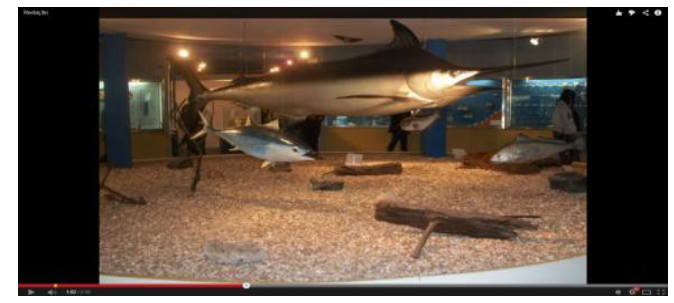

Figura 4: Relato de Viagem de um aluno

Nas práticas vivenciadas seguimos a sistematização do trabalho em etapas, o que possibilitou estabelecer a necessidade de elaborar um roteiro para a aplicação, organizando o trabalho. Na tentativa de direcionar o trabalho com narrativas digitais na escola, propomos sua organização, também em etapas, como modo de sistematizar a aplicação de uma proposta pedagógica de criação de narrativa. Essa proposta considera a produção textual embasada em gêneros e aliada às tecnologias digitais, promovendo o uso de multiletramentos para produzir narrativas. Essa sistematização está representada na Figura 5 .

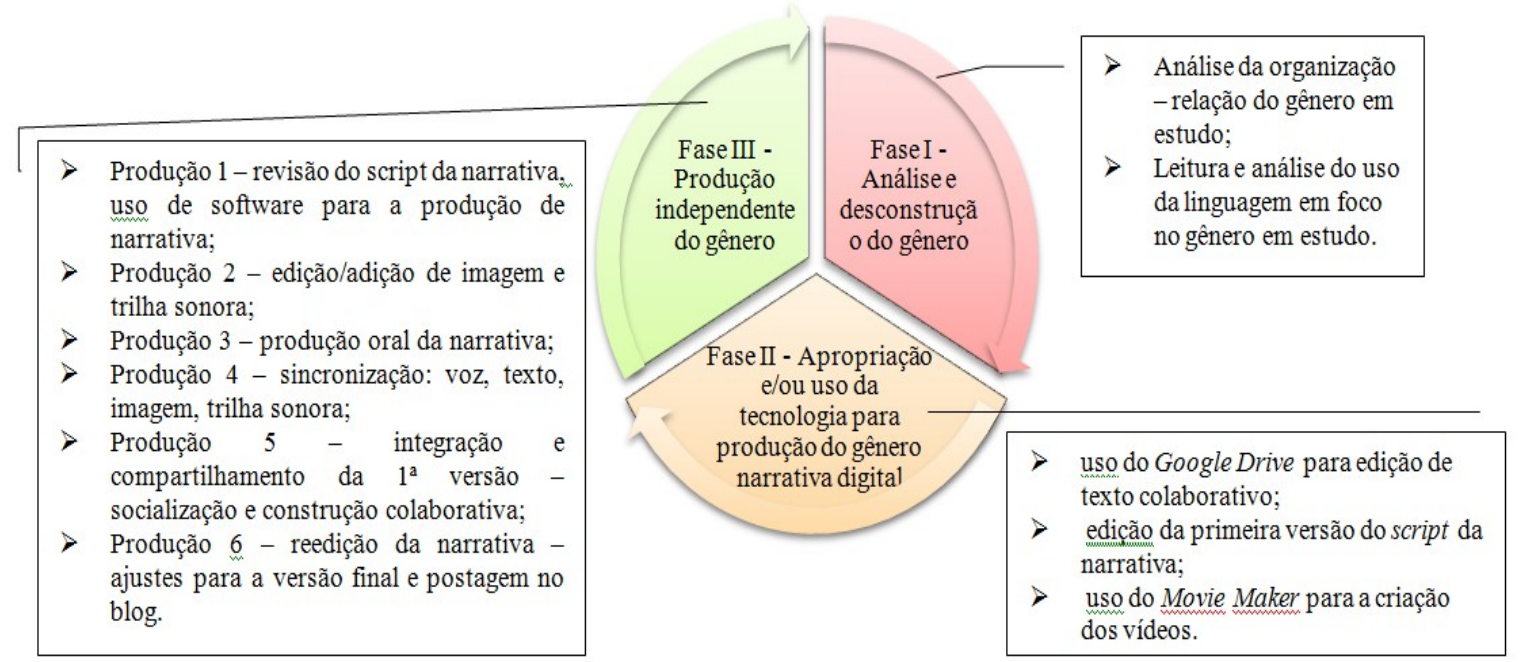

Figura 5: Proposta de etapas para produção de Narrativas Digitais

A proposta de uma metodologia em Fases para o ensino de produção textual por meio da produção de narrativas digitais, possibilita desenvolver um trabalho sistematizado, em sala de aula, aliando o uso da linguagem associado às tecnologias. A proposta consiste em três fases sucessivas de desenvolvimento de atividades, com o objetivo de sistematizar o trabalho, sendo elas: Fase I - nesse momento, os alunos fazem a leitura e análise de textos impressos e digitais que enfatizem o uso do gênero em estudo; Fase II - fase da apropriação e/ou uso da tecnologia para a produção da narrativa por meio da criação da primeira versão do script (roteiro) da narrativa, na qual são utilizados os softwares Google Drive, para a escrita compartilhada e o Movie Maker, para compor os vídeos; por fim, na Fase III, os alunos realizam a produção independente do gênero multimodal e, nessa fase, reorganizam a primeira versão de seus vídeos, a fim de que possam contemplar o gênero escolhido e o objetivo da tarefa, tornando-se alunos produtores de textos. 
Diante do exposto, podemos afirmar que as primeiras experiências foram relevantes para a elaboração da proposta destacada neste artigo, pois permitiram sistematizar a abordagem pedagógica em testagem. Além disso, as experiências reportadas possibilitaram investigar as possibilidades de uso das tecnologias, em uma escola pública, para produzir textos hipermidiáticos, viabilizando a aplicação deste estudo.

\section{Considerações finais}

A partir do trabalho proposto, consideramos que as práticas de multiletramentos de produção de narrativas digitais corresponderam às expectativas, cumprindo seu propósito inicial de promover a escrita contextualizada. Constatamos, ainda, que a produção textual, voltada para satisfazer as necessidades comunicativas pressupõe o ensino da LP voltado para aprimoramento de competências e habilidades que promovam a inclusão do aluno na sociedade atual. Para isso, além da necessidade de práticas de multiletramentos na escola, é preciso que o professor busque fundamentar seus conhecimentos para que seus objetivos sejam alcançados e possibilite melhorias nos processos de ensino e aprendizagem, principalmente, relacionados ao uso da linguagem.

Consideramos, também, a necessidade de um trabalho embasado na colaboração, em que realmente o professor assuma o papel de moderador e orientador da aprendizagem, dispondo-se a ensinar e aprender, aproximando-se do universo de seu aluno ao prepará-lo para o exercício consciente da cidadania. Para tanto, é preciso que este seja sujeito ativo e produtor nos processos de ensino e aprendizagem para que haja efetiva construção de conhecimento, fazendo o exercício de autoria de seus textos, ao utilizar a tecnologia como ferramenta de suporte e não simplesmente fonte de pesquisa.

A partir do trabalho realizado nas experiências, podemos destacar algumas constatações, tais como: a) a produção de textos hipermidiáticos incentiva os alunos a usar a linguagem para expressar-se com maior clareza; b) contar histórias usando a tecnologia aguça os sentidos e possibilita criar/recriar o mundo por meio de relatos reais e/ou imaginários, nos permitindo externar nossos medos e anseios; c) desenvolver um trabalho de uso da linguagem embasado em gêneros aproxima o aluno da tarefa de produção textual, que passa a ser vista como interessante, pois envolve comunicar-se com o outro; d) reafirma a necessidade da escrita contextualizada, voltada para a satisfação de necessidades comunicativas exigidas na contemporaneidade; e) a prática de multiletramentos proposta neste artigo promove o uso das múltiplas linguagens na escola e o aperfeiçoamento de competências e habilidades que possibilitem ao aluno inserir-se na sociedade moderna.

Ressaltamos, ainda, que o trabalho baseado em etapas, possibilitou organizar a aplicação da abordagem pedagógica e estabelecer passos essenciais na produção das narrativas para que auxiliem professor e aluno no processo de criação, aprimorando a prática pedagógica. Finalmente, consideramos que práticas inovadoras são necessárias para que a escola se insira no atual contexto sócio-histórico com o intuito de qualificar os processos de ensino e aprendizagem, principalmente quanto ao uso da linguagem e suas multiplicidades. Para isso, precisamos recorrer aos recursos disponíveis a fim de que a educação seja transformadora e que consiga promover a inserção/inclusão do aluno na sociedade, contribuindo efetivamente para sua formação, concebendo-o como cidadão, consciente de seu papel e capaz de interagir e intervir no seu meio de forma crítica e criativa. 


\section{Referências}

CECCHIN, A.S.; REIS, S. C. A produção de textos hipermidiáticos na aprendizagem da Língua Materna. In: OLIVEIRA, A. M.; ROSA, R. (Org.) Tic aplicada à educação: usos, apropriações e convergências. Santa Maria/RS: Facos - UFSM, 2013, p. 315-332.

COPE, B.; KALANTZIS, M. Multiliteracies: new literacies, new learning. Pedagogies: An Internacional Journal, n.4, v.3, 2009. p. 164-185.

HEBERLE, V. M. Multimodalidade e multiletramento: pelo estudo da linguagem como prática social multissemiótica. In: SILVA, K. A.; DANIELA, F. G.; MARQUES, S. M. K.; SALOMÃO, A. C. B. (Org.) A formação de professores de línguas: novos olhares, v.2, Campinas, São Paulo: Pontes Editores, 2012.

HYLAND, K. Genre pedagogy: language, literacy and L2 writing instruction. Journal of Second Language Writing, v. 16, p.148-164, 2007.

KENSKI, V. M. Educação e tecnologias: O novo ritmo da informação. 6. ed. Campinas/São Paulo: Papirus, 2012.

MOTTA-ROTH, D. O ensino de produção textual com base em atividades sociais e gêneros textuais. Revista Linguagem em (Dis)curso. v. 6, nº 3, set/dez 2006

MOTTA-ROTH, D.; HENDGES, G. Explorando modalidades retóricas sob a perspectiva da multimodalidade, Revista Letras, v. 20, nº 40, p. 43-66, jan./jun. 2010.

OHLER, J. Digital Storytelling in the Classroom: New Media Pathways to Literacy, Learning, and Creativity, Corwin press, 2008.

OLIVEIRA, M. M. Como fazer pesquisa qualitativa. Petrópolis, RJ: Vozes, 2007.

PAIVA, V. L. M. O. Narrativas multimídia de aprendizagem de língua inglesa: um gênero emergente. Revista Signos, vol.43, p. 183-203, 2010.

REIS, S. C.; GOMES, A. F. Podcasts para o ensino de Língua Inglesa: análise e prática de Letramento Digital. Calidoscópio (Online), v. 12, p. 367-379, 2014.

ROJO, R. H. R. (Org.); MOURA, E. (Org.). Multiletramentos na Escola. $1^{\text {a }}$. ed. São Paulo, SP: Parábola Editorial, 2012. 